\title{
Haploinsufficiency of Elastin Gene May Lead to Familial Cardiopathy and Pulmonary Emphysema
}

\author{
Jacoba J Louw, ${ }^{1,2 *}$ Geert Verleden, ${ }^{3}$ Marc Gewillig, ${ }^{1}$ and Koenraad Devriendt ${ }^{2}$ \\ ${ }^{1}$ Department of Congenital and Pediatric Cardiology, University Hospitals Leuven, Belgium \\ ${ }^{2}$ Centre for Human Genetics, University Hospitals Leuven, Katholieke Universiteit Leuven, Leuven, Belgium \\ ${ }^{3}$ Lung Transplantation Unit, University Hospitals Leuven, Belgium
}

Manuscript Received: 9 June 2011; Manuscript Accepted: 16 April 2012

\section{TO THE EDITOR:}

Wan et al. [2010] reported in this journal a non-smoking adult person with Williams-Beuren syndrome and emphysema, and raised the question if defects in the elastin gene are associated with increased susceptibility toward developing chronic obstructive pulmonary disease (COPD) and emphysema. Additional support that haploinsufficiency for the elastin gene could play a role in the pathogenesis of emphysema is supported by the observation of a functional mutation in the elastin gene in two independent persons with early onset COPD [Kelleher et al., 2005; Cho et al., 2009], as well as the fact that changes in the elastin gene are also described in cases of autosomal dominant form of cutis laxa (OMIM 123700) associated with severe premature emphysema [Rodriguez-Revenga et al., 2004; Urban et al., 2005]. ELNexpression plays a crucial role in development of the alveoli at both the alveolar duct and alveolar sac levels, most likely due to a defect in alveolar septal development and alveolar growth [Wendel et al., 2000; Shifren et al., 2006]. Mice $(E L N+/-)$ with about half $(45 \%)$ the levels of elastin compared to wild-type (WT) animals show macroscopically and microscopically normal lungs, with normal lobe numbers and major airway branching patterns. An increased inflammatory response to cigarette smoke was also noted. However, $h B A C-/-$ (human ELN transgene positive, mouse $E L N$ gene null) animals, with about one third of normal elastin expression levels and significantly decreased collagen levels, showed grossly abnormal pulmonary structure with severe congenital emphysema that is present from birth but not progressive. Finally, mice deficient in elastin $(E L N-/-)$ exhibit abnormalities in the lungs that are morphologically similar to emphysema [Shifren et al., 2006].

We present a family where an elastin gene mutation is associated with both cardiac and pulmonary manifestations, i.e., peripheral pulmonary stenosis (PPS), supravalvular aortic stenosis, and severe pulmonary emphysema. The family is Caucasian and the parents are unrelated.

The index patient, a boy, was referred shortly after birth to our Tertiary Pediatric Cardiology Unit after a cardiac murmur was heard at the first clinical examination. The diagnosis of an important PPS was made due to mild hypoplasia (3-4 mm at birth) of the pulmonary arteries. This initially led to mild right ventricular hypertrophy, which subsequently regressed with sufficient growth
How to Cite this Article:

Louw JJ, Verleden G, Gewillig M, Devriendt K. 2012. Haploinsufficiency of elastin gene may lead to familial cardiopathy and pulmonary emphysema.

Am J Med Genet Part A.

of the pulmonary arteries. A notch in the ascending aorta was also present on echocardiography, but without a pressure gradient and only a minimal degree of aortic insufficiency, thus posing no hemodynamic consequences at birth. An important degree of aortic stenosis and a mild degree of insufficiency gradually developed with subsequent left ventricular hypertrophy, by the age of 2 years surgical correction was necessary with angioplasty.

The father of our patient is known to have supra-aortic stenosis for which a patch plasty was performed at the age of 7 years. He also underwent bilateral lung transplantation due to pulmonary emphysema at the age of 45 years with presenting clinical symptoms at the age of 36 years. He was a heavy smoker with a total of 24 pack years. Alpha 1-antitrypsin deficiency (A1AT) was excluded; $2.03 \mathrm{~g} / \mathrm{L}$ in serum as well as absence of the following recurrent mutations: p.E342K (Z-variant) in exon 5 and p.E264V (S-variant) in exon 3. Furthermore, the paternal grandfather died at the age of 45 years due to pulmonary emphysema. He was also a smoker and was known to have a cardiopathy, although more specific detail is not available.

Neither our index patient, nor his father had any dysmorphic features, as determined by an experienced clinical geneticist. The father of our patient and his grandfather have no siblings, but have the same phenotype, i.e., cardiopathy and a history of pulmonary

\footnotetext{
${ }^{\star}$ Correspondence to:

Jacoba J Louw, M.D., UZ Leuven - Pediatric Cardiology, Herestraat 49 Leuven 3000, Belgium. E-mail: jacoba.louw@uzleuven.be Article first published online in Wiley Online Library (wileyonlinelibrary.com): 00 Month 2012

DOI 10.1002/ajmg.a.35464
} 
emphysema presenting at a young age. There were no reported phenotypes in the rest of the family.

Due to the paternally known cardiopathy, the suspicion of a haplosufficiency in the elastin gene with dominant inheritance was strongly suspected. Fluorescence in situ hybridization (FISH) using an ELN probe did not show a deletion in this gene, but a heterozygous ELN point mutation was found in both the father and our index patient: c.2T $>\mathrm{C}$ which leads to p.M1T. This is responsible for a change in the start codon methionine, and due to the fact that no other in-frame methionine is present in the elastin mRNA, this mutation is predicted to lead to the absence of the elastin protein. This mutation has not been reported before, and is not a known polymorphism or rare variant.

Considering this impressive family history, we hypothesize that a mutation in this elastin gene might be responsible for an earlier or more severe presentation of pulmonary emphysema. Additional known risk factors, such as smoking, will make these patients more susceptible to emphysema. Additional known emphysema risk factors, i.e., a carrier status for A1AT deficiency could also have an effect but were excluded in the father. Our index patient and his father, in whom the genotype was confirmed, both clearly presented with symptoms at a young age. Our index patient is 6 years old and thus too young to correctly perform pulmonary function testing. Considering that he currently has no respiratory symptoms, we chose not to perform a CT scan, as this will not have any clinical implications. Furthermore, his father only presented with respiratory symptoms in the third decade.

This family size is too small to be able to make a conclusion of segregation with disease. Only two affected individuals are alive, and both carry the elastin mutation. The grandmother of the index was not available for testing, and the mother and siblings of our index patient were not tested, due to the fact that they have a normal phenotype and a normal cardiac echocardiography.
This information is of utmost importance for the future health of this young patient; we strongly discouraged smoking or exposure to secondary smoking. In a more general way, this observation lends further support to the notion that haploinsufficiency for ELN is a risk factor for emphysema.

\section{REFERENCES}

Cho MH, Ciulla DM, Klanderman BJ, Hersh CP, Litonjua AA, Sparrow D, Raby BA, Silverman EK. 2009. Analysis of exonic elastin variants in severe, early-onset chronic obstructive pulmonary disease. Cell Mol Biol 40: 751-755.

Kelleher CM, Silverman EK, Broekelmann T, Litonjua AA, Hernandez M, Sylvia JS, Stoler J, Reilly JJ, Chapman HA, Speizer FE, Weiss ST, Mecham RP, Raby BA. 2005. A functional mutation in the terminal exon of elastin in severe, early-onset chronic obstructive pulmonary disease. Am J Respir Cell Mol Biol 33:355-362.Epub 2005 Aug 4.

Rodriguez-Revenga L, Iranzo P, Badenas C, Puig S, Carrió A, Milà M. 2004. A novel elastin gene mutation resulting in an autosomal dominant form of cutis laxa. Arch Dermatol 140:1135-1139.

Shifren Adrian, Durmowicz Anthony G, Knutsen Russell H, Hirano Eiichi, Mecham Robert P. 2006. Elastin protein levels are a vital modifier affecting normal lung development and susceptibility to emphysema. Am J Physiol Lung Cell Mol Physiol 292:L778-L787.

Urban Z, Gao J, Pope FM, Davis EC. 2005. Autosomal dominant cutis laxa with severe lung disease: Synthesis and matrix deposition of mutant tropoelastin. J Invest Dermatol 124:1193-1199.

Wendel DP, Taylor DG, Albertine KH, Keating MT, Li DY. 2000. Impaired distal airway development in mice lacking elastin. Am J Respir Cell Mol Biol 23:320-326.

Wan ES, Pober BR, Washko GR, Raby BA, Silverman EK. 2010. Pulmonary function and emphysema in Williams-Beuren syndrome. Am J Med Genet Part A 152A:653-656. 